\title{
Heat Transfer Performance Analysis of Screen Mesh Wick Heat Pipe Using CuO Nano Fluid
}

\author{
Shylesha V. Channapattana ${ }^{1 *}$, Saurabh B. Raut ${ }^{2}$, Abhay A. Pawar ${ }^{1}$, Srinidhi Campli ${ }^{3}$, \\ Sandeep S. Sarnobat ${ }^{4}$, Tapobrata Dey ${ }^{4}$ \\ ${ }^{1}$ D. Y. Patil College of Engineering, Ambi, Talegaon Dabhade, Pune, INDIA \\ 2 Department of Mechanical Engineering, JSPM NTC RSSOER, Pune, Maharashtra, INDIA \\ ${ }^{3}$ SRTTC Faculty of Engineering, Kamshet, Pune, INDIA \\ ${ }^{4}$ D. Y. Patil College of Engineering, Akurdi, Pune, INDIA
}

*Corresponding Author: shylesha@gmail.com

Citation: Channapattana, S. V., Raut, S. B., Pawar, A. A., Campli, S., Sarnobat, S. S. and Dey, T. (2019). Heat Transfer Performance Analysis of Screen Mesh Wick Heat Pipe Using CuO Nano Fluid. European Journal of Sustainable Development Research, 3(2), em0080. https://doi.org/10.20897/ejosdr/3927

Published: March 3, 2019

\begin{abstract}
In this paper, the effect of multilayer screen mesh wicks and $\mathrm{CuO}$ nano-fluid as working fluid is investigated on the performance of heat pipe. Three heat pipes were fabricated with different layers of screen mesh wicks to improve capillary action of working fluid. Heat pipes of $350 \mathrm{~mm}$ length and $19.5 \mathrm{~mm}$ diameter were used. The different mesh configurations used in this work were 100+150 mesh, 100+2X150 mesh and 4X150 meshes. The concentration of $\mathrm{CuO}$ nano-fluids in the experiments was maintained at $1 \%$ by weight of water. The heat pipes are tested with water and $\mathrm{CuO}$ as working fluid for different heat inputs of $35 \mathrm{~W}$, $50 \mathrm{~W} 75 \mathrm{~W}, 100 \mathrm{~W}$ and $120 \mathrm{~W}$. The thermal resistance and heat transfer rate were determined. It is found that the thermal resistance decreases with increase in heat input. There is increase in heat transfer rate in case of $\mathrm{CuO}$ nanofluid loading in ordinary water compared to distilled water as working fluid. For all orientation the maximum heat transfer through the heat pipe increased as the number of mesh layer of the wick is increased. The heat transfer rate is found to be maximum at $100 \mathrm{l} / \mathrm{h}$ mass flow rate compared to that of 150 1/h.
\end{abstract}

Keywords: heat pipe, cuprous oxide, thermal resistance, multilayer mesh wick

\section{INTRODUCTION}

The heat pipe has been widely used for cooling high power density devices due to its high effective conductivity, good heat spreading capability and geometric flexibility. The heat pipe is a highly effective passive device for transmitting heat at high rates over considerable distances with extremely small temperature drops, exceptional flexibility, simple construction and easy control with no external pumping power (Faghri, 1995). There has been renewed interest in the use of heat pipes for thermal management due to increasing heat flux requirements and thermal constraints in many industrial applications. The thermal performance of a wicked heat pipes is typically characterized by both its maximum heat transport rate and its effective thermal resistance. In many moderatetemperature applications, the heat transport rate is typically limited by the capillary pressure that can be generated by the wick structure. Hence, there has been considerable research focused on developing better models to predict the pressure drop that occurs in wicked heat pipes. This has included numerous numerical and analytical investigations that have solved the coupled equations for liquid flow through the wick and the vapour flow for a 
range of different conditions, including multiple heat sources and transient start-up of the heat pipe (Kempers et al., 2006).

Kempers et al. carried out an experimental study to determine the effect of the number of mesh layers and amount of working fluid on the heat transfer performance of copper-water heat pipes with screen mesh wicks. They found that the effective thermal resistance decreases with an increase in heat flux, and approaches an approximately constant value at higher heat fluxes. This non-linearity in the thermal resistance is larger for wicks with fewer mesh layers. For all orientations, the maximum heat transfer through the heat pipe increased as the number of mesh layers of the wick was increased (Kempers et al., 2006). Yao et al. shows that the heat transfer improvement of the $\mathrm{CuO}$ nano-fluid heat pipe was the most effective, followed (Yao et al., 2015) by $\mathrm{Al}_{2} \mathrm{O}_{3}$ and so $\mathrm{SiO}_{2}$. Therefore, considering the dual factors of stability and thermal physical phenomenon, $\mathrm{CuO}$ nano fluids were thought of as the best one and considered in the present work. Solomon et al. carried experimental investigation on study of thermal performance of a heat pipe operated with nanoparticle coated wick. The total resistance of heat pipe operated with coated wick was lower than that of conventional (Putra et al., 2012) one and it decreased with increasing heat input. At the evaporator section, 40 percent thermal resistance reduction with 40 percent heat transfer coefficient enhancement were observed. Also decrement in total resistance was observed by about 19\%, $15 \%$, and 14\% for 100,150 and $200 \mathrm{~W}$ respectively (Solomon et al., 2012). Yang et al. (Yang et al., 2008) carried out an experiment of studying the heat transfer performance of a horizontal micro-grooved heat pipe using $\mathrm{CuO}$ nanofluid as the working fluid and found that the heat transfer coefficients of the evaporator section can be averagely enhanced by $46 \%$ and the critical heat flux also enhanced by $30 \%$ when substituting the $1.0 \mathrm{wt} \% \mathrm{CuO}$ nanofluids for water. The heat resistance of (Ghanbarpour et al., 2015) the heat pipe decreases obviously and the maximum power of the heat pipe increases remarkably when deionized water is substituted by $1.0 \mathrm{wt} \% \mathrm{CuO}$ nanofluid.

Asirvatham et al. presents the improvement in heat transfer performance of a heat pipe using silver nanoparticles dispersed in DI (De-Ionized) water. The heat pipes were tested for heat inputs ranging from $20 \mathrm{~W}$ to $100 \mathrm{~W}$ in five steps for removing heat from power transistors in electronics and processors in computers. The effect of various operational limits and test parameters such as heat inputs, volume fraction, vapour temperature on the thermal resistance, evaporation and condensation heat transfer coefficients were investigated. The tested silver nanoparticles volume concentration ranged from $0.003 \%$ to $0.009 \%$ with average nanoparticle diameter of $58.35 \mathrm{~nm}$. The experimental results are evaluated in terms of performance metrics by direct measurement of vapour temperatures in the Centre core of heat pipe (Lazardas et al., 2013). Hassan et al. carried out experimental and numerical study on cooling of an electronic component using flat heat pipe having water based $\mathrm{Cu}, \mathrm{CuO}$ and $\mathrm{Al} 2 \mathrm{O} 3$ nanoparticles as working fluid. They have considered the effects of diameter of nanoparticles, volume fraction, wick porosities and wick thicknesses on performance of heat pipe. They showed that the maximum temperature of the heat pipe decreases by using nanofluids at different wick porosities and thicknesses. The (Ersoz and Yildiz, 2016) temperature of the heat pipe decreases with decreasing the diameter and with increasing the volume fraction of the solid nano particles (Hassan and Harmand, 2015). Brahim and Jemni used Al2O3 and $\mathrm{CuO}$ based water nanofluids were used in heat pipe. They found reduction of $68 \%$ thermal resistance for $9 \% \mathrm{CuO}$ nanofluid concentration. Nanofluid based heat pipe (Brahim and Jemni, 2016) is able to dissipate up to 26\% more heat without experiencing an increase in the wall temperature. The heat pipe behavior under normal and high heat flux conditions with two boundary conditions in the condenser region was (Brahim and Jemni. 2013) investigated and found that the adiabatic region plays a major role in maintaining heat pipe stability. Three-dimensional steady state model for thermal and hydrodynamic transport in heat pipe is developed in cylindrical polar coordinate coupling the three regions of heat pipe. The (Brahim and Jemni. 2012) maximum circumferential velocity occurred near the liquid vapor interface and increase when the heat loads increase.

The present is focussed on application of aqueous based $\mathrm{CuO}$ nanofluids in multilayer screen mesh wick heat pipe. Effects of the number of mesh and mass flow rate on the thermal performance of multilayer screen mesh wick heat pipe were investigated. The mesh configurations used are 100+150 mesh, 100+2 X 150 mesh, and 4 X 150 meshes. The effect of variable source temperature and variable heat loads on thermal resistance and heat transfer rate were also investigated.

\section{PROPERTIES OF NANOFLUID}

Copper oxide nanoparticle of size $25-30 \mathrm{~nm}$ is used in the present work and base working fluid used is distilled water. The $\mathrm{CuO}$ nanofluid was prepared by two step method. The $\mathrm{CuO}$ nano-particles of the above size were procured from manufacturer which was produced using a catalytic chemical vapor deposition. The $\mathrm{CuO}$ nano particles were added to distilled water. Citrate surfactant is used for the purpose of suspension. Ultrasonic homogenizer was used for mixture preparation. Nano-fluid volume concentration of $1 \%$ is used in this study. The properties of $\mathrm{CuO}$ nanoparticle and the base fluid is shown in Table 1. 
Table 1. Properties of $\mathrm{CuO}$ and Base fluid

\begin{tabular}{lcccc}
\hline S.N. & Nanoparticle/Fluid & Density $\left.\mathbf{( k g} / \mathbf{m}^{3}\right)$ & Thermal Conductivity $(\mathbf{W} / \mathbf{m K})$ & Specific Heat $(\mathrm{J} / \mathbf{k g K})$ \\
\hline 1 & $\mathrm{CuO}$ & 6310 & 32.9 & 550.5 \\
\hline 2 & Water & 997.5 & 0.628 & 4178 \\
\hline
\end{tabular}

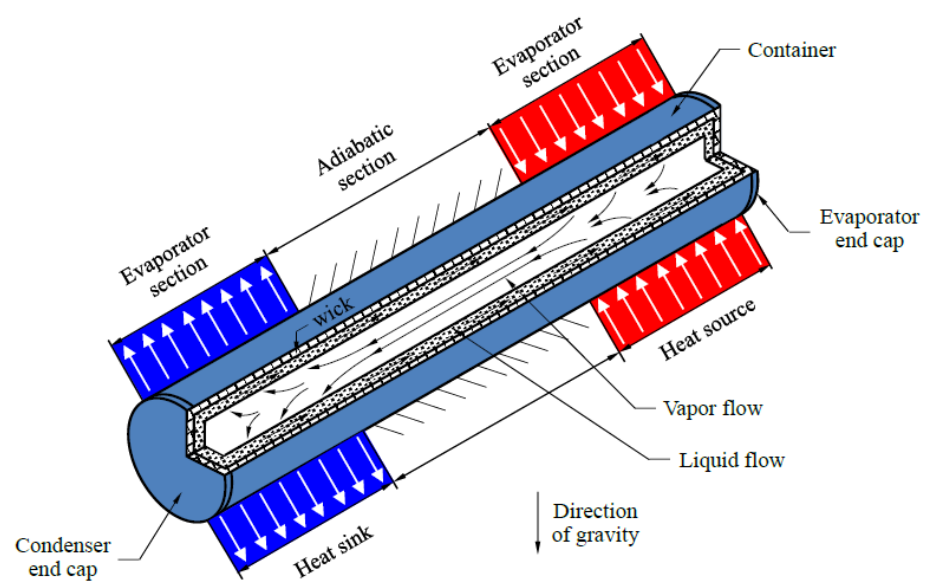

Figure 1. Schematic diagram of Heat Pipe (Yao et al., 2015)

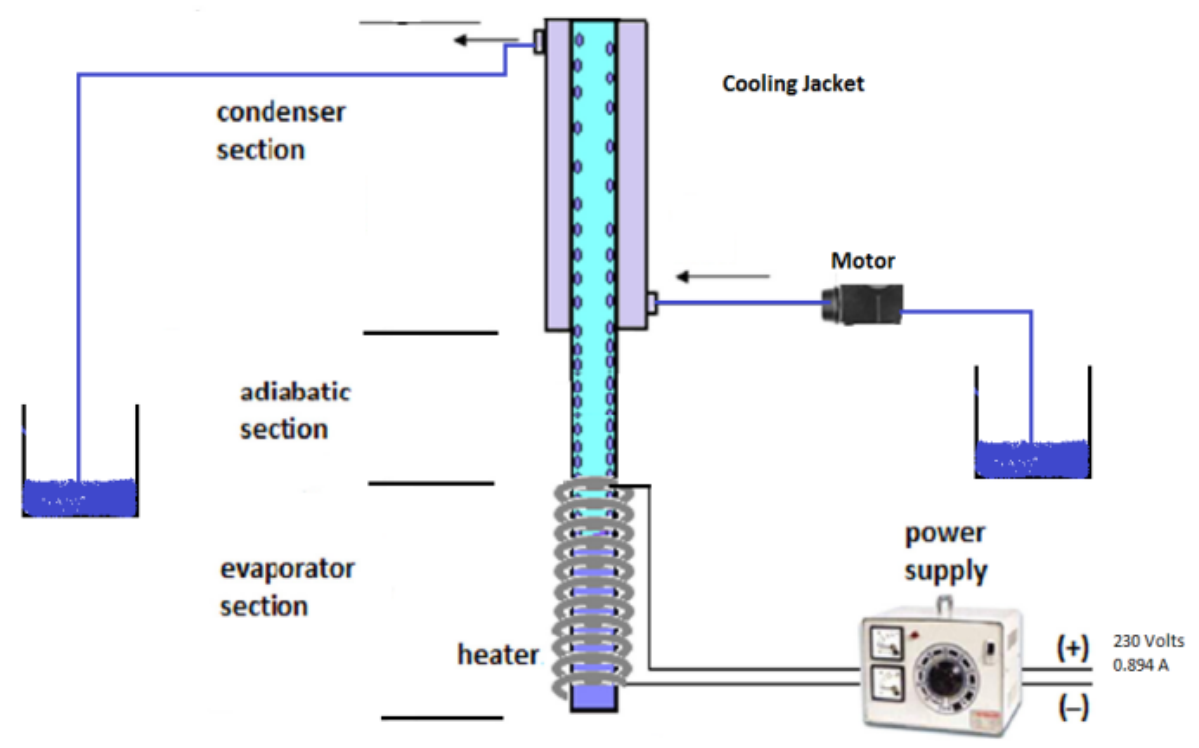

Figure 2. Schematic diagram of Heat Pipe experimental setup

\section{EXPERIMENTAL PROCEDURE}

The schematic diagram of experimental facility used for the present investigation is shown in Figure 2. The heat pipe is mounted on a variable angle holder, which is used to vary the inclination angle of heat pipe from horizontal position to $30^{\circ}, 60^{\circ}$ and $90^{\circ}$ respectively as shown in Figure 1. An autotransformer is provided with the circuit to increase heat input to the evaporator section of heat pipe. Thermocouples are fixed in evaporator, condenser and adiabatic sections. These thermocouples are connected with data acquisition system to measure the temperature values at each position. A personal computer is connected with the system to monitor and record the readings. Heat rejection in the condenser section is carried away by the cooling water. The mass flow rate and inlet temperature of cooling water both are maintained at $20 \mathrm{~kg} / \mathrm{hr}$ and $25^{\circ} \mathrm{C}$ respectively. The readings are noted under steady state conditions. Table 2 represents the detailed information of the heat pipe.

The schematic diagram of experimental set-up used in the present investigation is shown in Figure 2. It consists of three band heaters (maximum power output of $125 \mathrm{~W}$ ), Watt meter and a dimmer knob to provide required power by the heaters. The heat pipe is sealed at bottom and top after loading of working fluid. The bottom was 
Table 2. Specifications of Heat Pipe

\begin{tabular}{ll}
\hline Description & Value \\
\hline Container Material & Copper \\
\hline Cooling jacket Material & Stainless steel \\
\hline \multirow{2}{*}{ Geometry } & O.D.=20.5mm \\
& I.D. $=19.5 \mathrm{~mm}$ \\
\hline Total length of pipe (L) & Cooling jacket Diameter $40 \mathrm{~mm}$ \\
\hline Length of evaporator section (Le) & $350 \mathrm{~mm}$ \\
\hline Length of adiabatic section (La) & $100 \mathrm{~mm}$ \\
\hline Length of condenser section (Lc) & $100 \mathrm{~mm}$ \\
\hline
\end{tabular}

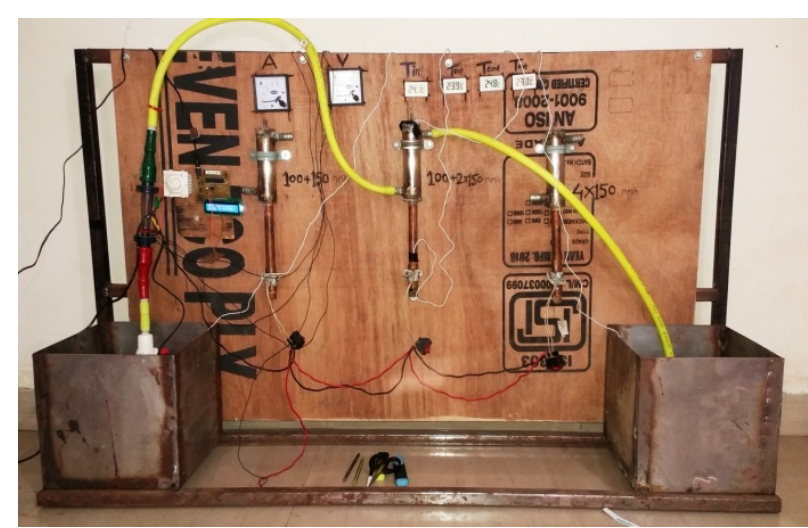

Figure 3. Actual experimental setup

sealed permanently and top was sealed by a removable cork, it was ensured that the working fluid operates in the vacuum created inside the heat pipe.

Water jacket is attached to the condenser section for forced convection to occur at this section. Four thermocouple wires were fixed along the exterior of heat pipe. At the outset each thermocouple sets were fused together at the tip points and attached to the outer surface of a heat pipe. The other ends of the thermocouple wires were linked with the digital thermocouple reader by means of connecting wires. Thermocouples were positioned on the external surface of the heat pipe configured as, two at evaporator section, two at adiabatic section and two at condenser section.

The experimental apparatus loop consists of the mixed solution test section, cold water loop and record data system. The close-loop of cold water starts with a 10 liter storage tank. When the temperature input is given to the evaporator section, the cold water is then, pumped out of the storage tank passing through a flow controlled valve to test section (Condenser section), and then returned to the storage tank. The flow rate of the cold water is controlled with the help of flow control valve. The evaporator section of the heat pipe is fitted with the band heater which is supplied by $220 \mathrm{~V}$ AC power supply, while the condenser section is inserted into cooling chamber. Thermocouples with $\mathrm{T}$-type are used so as to measure the temperature of evaporator section, adiabatic section and condenser section by mounting on the heat pipe wall surface and fixed with insulating tape.

The inlet and outlet temperatures of the cooling water are also measured using two K-type thermocouples. The thermocouple positions of heat pipe tested with distilled water and nanofluid are presented in Figure 3. The flow rate of the cooling water is measured when the heat pipe operates steadily. The heat pipes with nanofluid are tested for the heat input varying from $35 \mathrm{~W}$ to $120 \mathrm{~W}$. After the insulation of heater and the adiabatic section, the power supply to the resistance heater unit is turned on. The heat input is varied using the variable transformer from 35 $\mathrm{W}$ to $120 \mathrm{~W}$. Temperatures of the heat pipe and inlet and outlet temperatures of the cooling water are monitored by the data acquisition unit (Figure 2). The mass flow rate of cooling water at the condenser is measured when the heat pipe operates at steady state.

A cooling jacket was attached to the heat pipe wall in the condenser section at the top. The flow rate, the coolant temperatures at the inlet and outlet of the cooling block were used to estimate the amount of heat actually transported through the heat pipe, where $\mathrm{m}_{f}$ and $\mathrm{C}_{p}$ represent mass flow rate and specific heat of coolant. A series of experiments was conducted during this study against variations in the mesh wick heat pipes, working fluid, heat input.

The observations were taken by keeping mass flow rate at 100 and $150 \mathrm{l} / \mathrm{h}$ respectively; accordingly we changed the tilt angle of heat pipe. Then for the TPCT we performed the same procedure and the performance characteristics are obtained with the help of collected data, with the help of which one can understand the difference between Heat Pipe and TPCT heat pipe and one can choose the heat pipe which is necessary provide the required work for their particular operation. 


\section{MATHEMATICAL EQUATIONS}

Heat transferred by the heat pipe is calculated using the following heat balance equation 1 .

$$
Q_{\text {out }}=m C_{p}\left(T_{\text {out }}-T_{\text {in }}\right)
$$

where $Q_{\text {out }}$ is the heat transfer rate, $m$ is the mass flow rate of working fluid, $T_{\text {out }}$ is the outlet temperature of fluid flowing through cooling jacket and $T_{i n}$ is inlet temperature of fluid flowing through jacket.

The overall thermal resistance $(R)$ of the heat pipe is a measure of its thermal performance which is defined as the ratio of the temperature difference to a given heat load is calculated by equation 2 .

$$
R_{t h}=\frac{T_{e v p}-T_{\text {cond }}}{Q}
$$

where $R_{t h}$ is the thermal resistance, $T_{e v p}$ is evaporator temperature, $T_{c o n d}$ is Condenser temperature and $Q$ is the heat Input.

The effective thermal conductivity can be calculated by equation 3 .

$$
K_{\text {eff }}=\frac{Q_{\text {out }} \cdot L_{\text {eff }}}{A_{c} \cdot\left(T_{\text {evp }}-T_{\text {cond }}\right)}
$$

where $K_{e f f}$ is the effective thermal conductivity, $A_{c}$ is cross section area, $L_{e f f}$ is effective length, $L_{\text {adiabatic }}$ is length of adiabatic section, $L_{\text {cond }}$ is length of condenser section and $L_{\text {evap }}$ is length of evaporator section. Effective length of heat transfer can be calculated by the equation, $L_{\text {eff }}=L_{\text {adiabatic }}+0.5\left[L_{\text {evap }}+L_{\text {cond }}\right]$.

\section{RESULT AND DISCUSSION}

The observations and calculations provide us with the distinct values of heat transfer rate with respect to heat inputs. Along with this the various other heat transfer parameters are compared to meet the objectives of gathering the result with varying mass flow rate and the variability in heat transfer property with different working fluids.

Figures 4 to 11 show the comparison of heat output obtained with varying heat inputs for different heat pipe meshes with $\mathrm{CuO}$ Nano fluid and water as a working fluid for particular flow rate. The three meshes considered for the experimentation are 4 X 150 Mesh, 100+2 X 150 Mesh and $100+150$ Mesh. Heat inputs considered for experimentation at the evaporator section are $35 \mathrm{~W}, 50 \mathrm{~W}, 75 \mathrm{~W}, 100 \mathrm{~W}$ and $120 \mathrm{~W}$. Also the heat transfer properties were investigated by considering the mass flow rate of $100 \mathrm{l} / \mathrm{h}$ and $150 \mathrm{l} / \mathrm{h}$ at the condenser section.

Figure 4 shows heat output for different heat inputs for three different meshes with $\mathrm{CuO}$ as a working fluid at 1001/h. The heat pipe with mesh 4 X 150 shows better heat transfer rate amongst the tree heat pipes followed by $100+2$ X 150 mesh and 100+150 mesh. At lower heat input of $35 \mathrm{~W}$ the heat transfer rate obtained is quite less; this is due to the vapor pressure limit of heat pipe.

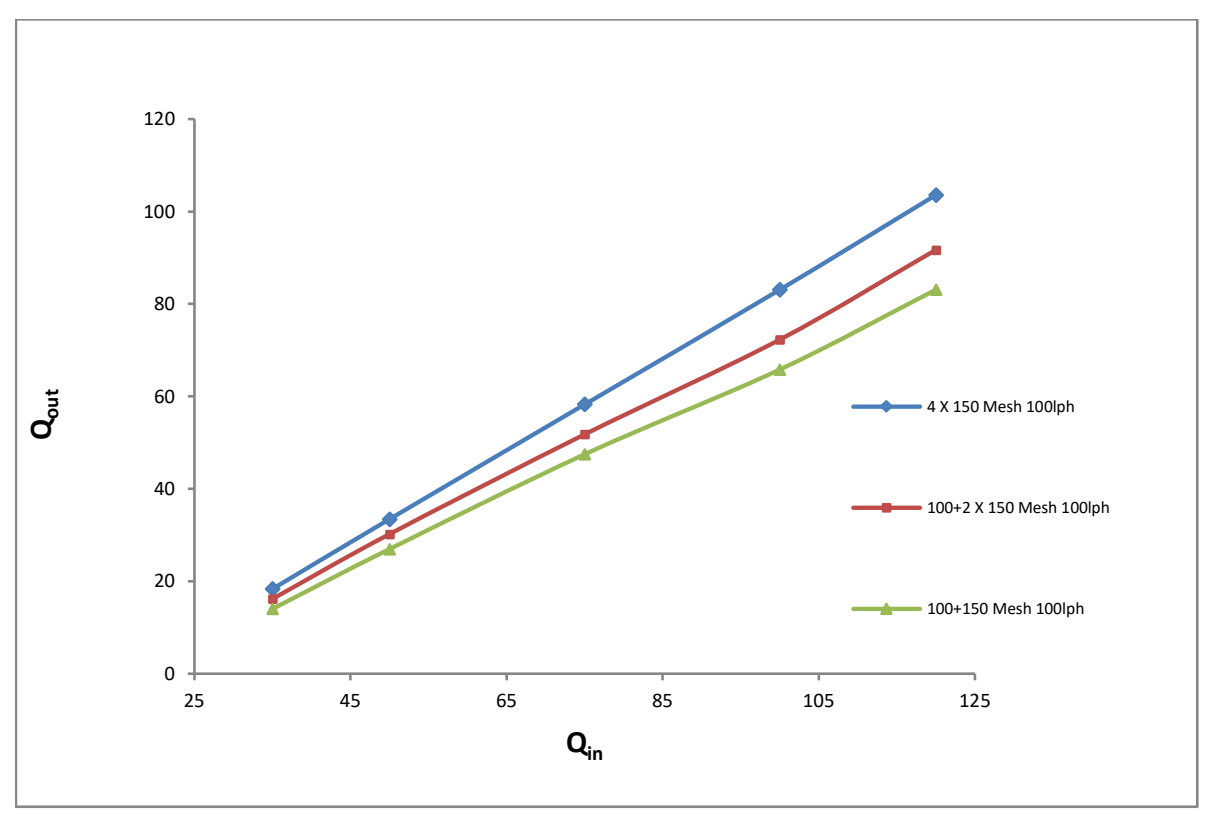

Figure 4. Heat Transfer rate with $\mathrm{CuO}$ nanofluid for different Mesh and heat inputs at $100 \mathrm{l} / \mathrm{h}$

(C) 2019 by Author/s 


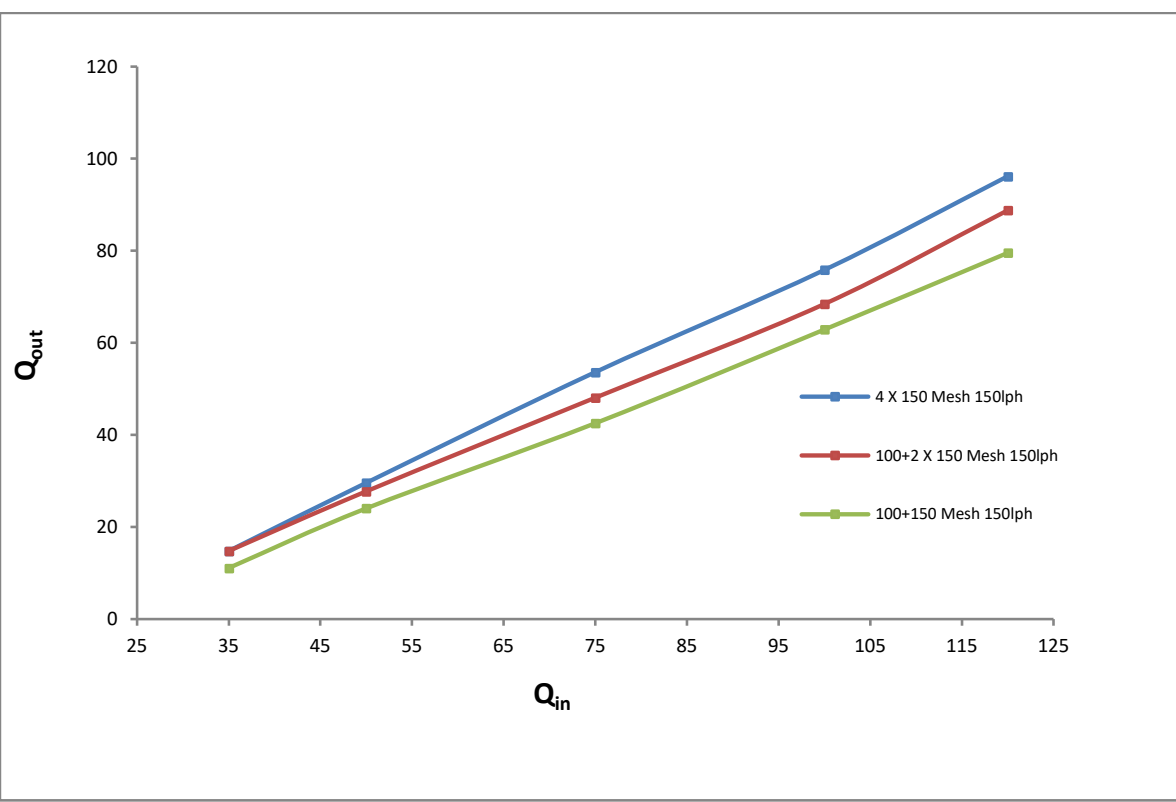

Figure 5. Heat Transfer rate with $\mathrm{CuO}$ nanofluid for different Mesh and heat inputs at $150 \mathrm{l} / \mathrm{h}$

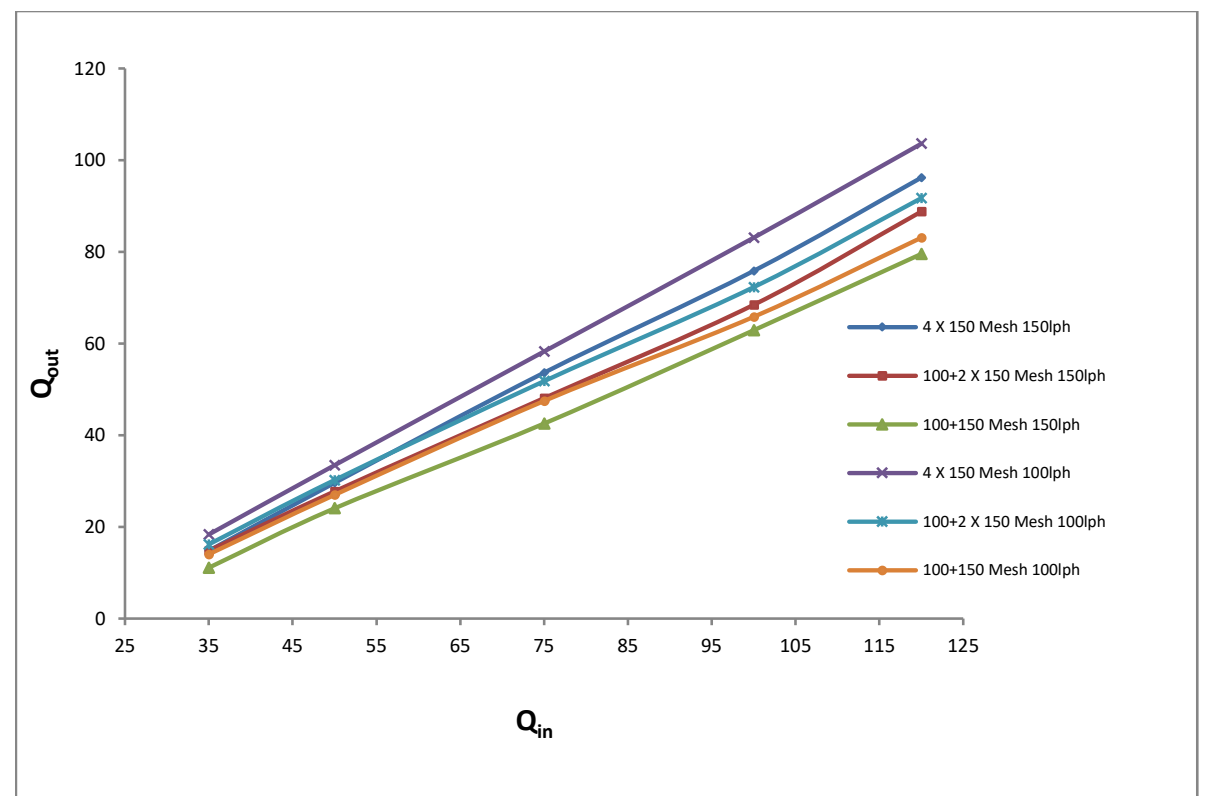

Figure 6. Heat Transfer rate with $\mathrm{CuO}$ nanofluid for different Mesh and heat inputs at 100 and 150 1/h

Figure 5 shows heat output for different heat inputs for three different meshes with $\mathrm{CuO}$ as a working fluid at 1501/h. The heat pipe with mesh 4 X 150 again shows better heat transfer rate amongst the three heat pipes followed by $100+2$ X 150 mesh and 100+150 mesh. It is also observed that the condenser section of heat pipe seems to be a bit cooler for $1501 / \mathrm{h}$ mass flow rate that that of $1001 / \mathrm{h}$. Increase in number of meshes shows improvement in heat transfer properties upto certain extent only. This may be because of increase in meshes would make the passage narrow for working fluid which at a certain point would be the prime reason for clogging of heat pipes.

Figure 6 shows heat output for different heat inputs and mass flow rate. The mass flow rate considered is $1001 / \mathrm{h}$ and $1501 / \mathrm{h}$. The heat pipe with mesh 4 X 150 shows better heat transfer rate at $100 \mathrm{l} / \mathrm{h}$ compared to others. It is also clear that better result is obtained for $100 \mathrm{l} / \mathrm{h}$ mass flow rate as compared to $1501 / \mathrm{h}$. The better heat transfer rate is obtained at lower mass flow rate due to better heat transfer between heat pipe condenser section and the water that needs to be preheated but the cooling of condenser section is slower hence condenser section works comparatively at a higher temperature. At $150 \mathrm{l} / \mathrm{h}$ the heat transfer rate from condenser section to the water that needs to be preheated is lesser than that of $100 \mathrm{l} / \mathrm{h}$ because at $150 \mathrm{l} / \mathrm{h}$, the time of contact between condenser and water is less. On the other hand cooling of condenser section is better than that of $100 \mathrm{l} / \mathrm{h}$. 


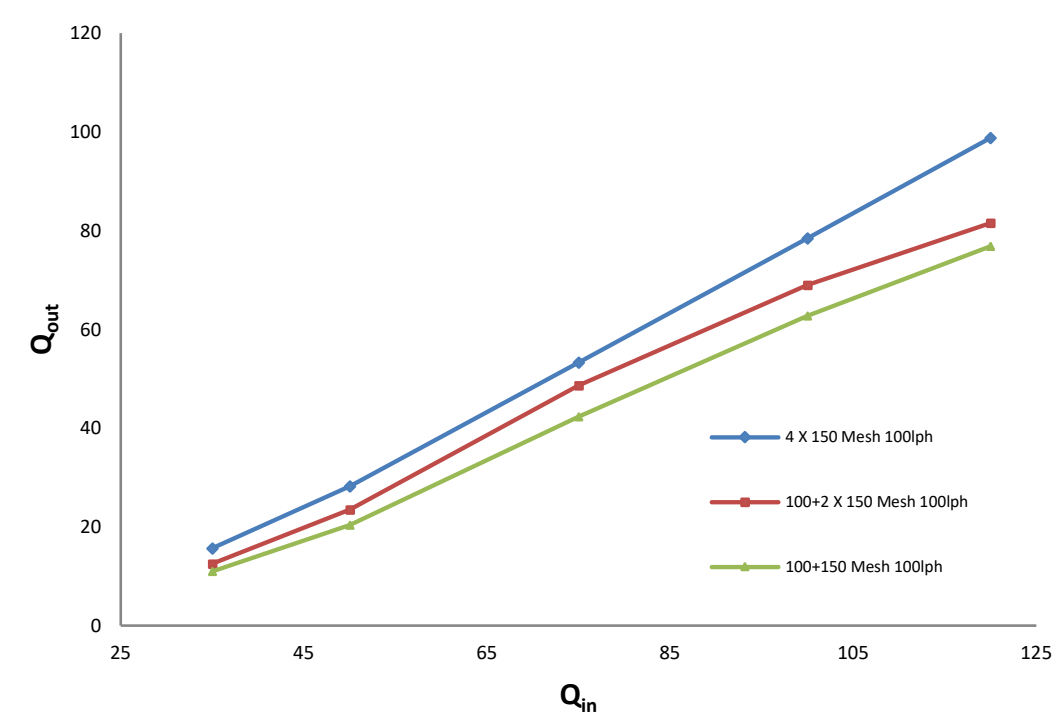

Figure 7. Heat Transfer rate with water for different Mesh and heat inputs at $100 \mathrm{l} / \mathrm{h}$

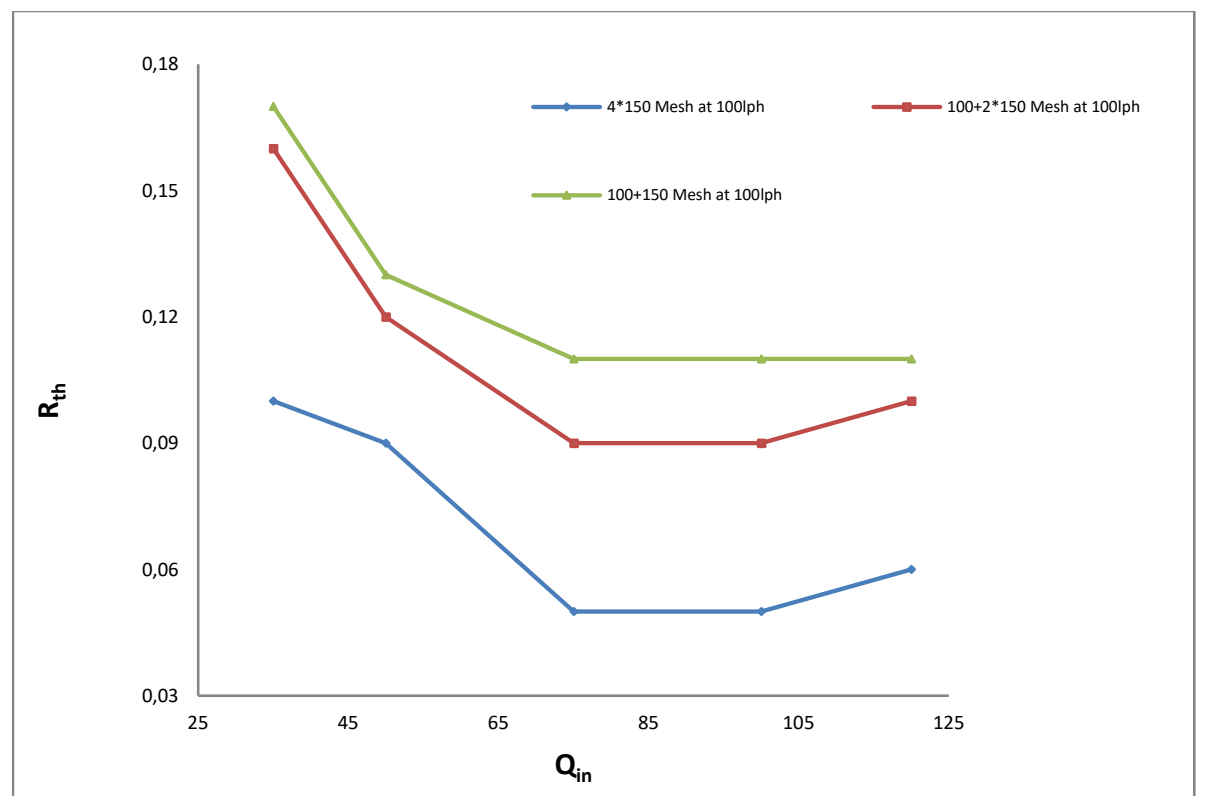

Figure 8. Thermal resistance for different heat with $\mathrm{CuO}$ nanofluid for different Mesh at $100 \mathrm{l} / \mathrm{h}$

Figure 7 shows heat output for different heat inputs and mass flow rate for different meshes with $\mathrm{CuO}$ as a working fluid. Mesh 4 X 150 shows better result than 100+2 X 150 mesh followed by 100+150 mesh at 100 l/h this is because 4 X 150 mesh have better contact area along with better capillary action.

Figure 8 shows comparison of heat output for both working fluids i.e. $\mathrm{CuO}$ nano fluid and Water for different heat input rates. It is clear that $\mathrm{CuO}$ nano fluid shows better heat transfer rate than that of Water in every mesh. Also heat output is found to be maximum for the 4 X 150 mesh for both $\mathrm{CuO}$ nano fluid as well as water.

Figure 9 and Figure 10 shows thermal resistance for different heat inputs for $\mathrm{CuO}$ nano fluid for 100 and 150 l/h respectively. Figure 11 shows thermal resistance for different heat inputs for water at $150 \mathrm{l} / \mathrm{h}$ as a working fluid. From Figure 9 and 10 it is clear that the thermal resistance is higher for $100+150$ mesh and lower for $4 \mathrm{X}$ 150 mesh with $\mathrm{CuO}$ as a working fluid. Similarly Figure 11 shows that the thermal resistance for 100+150 mesh is higher and lower for 4 X 150 mesh with water as a working fluid. It is observed that for lower heat inputs the thermal resistance is higher initially and with further increase in heat input the thermal resistance seems to be reduce. 


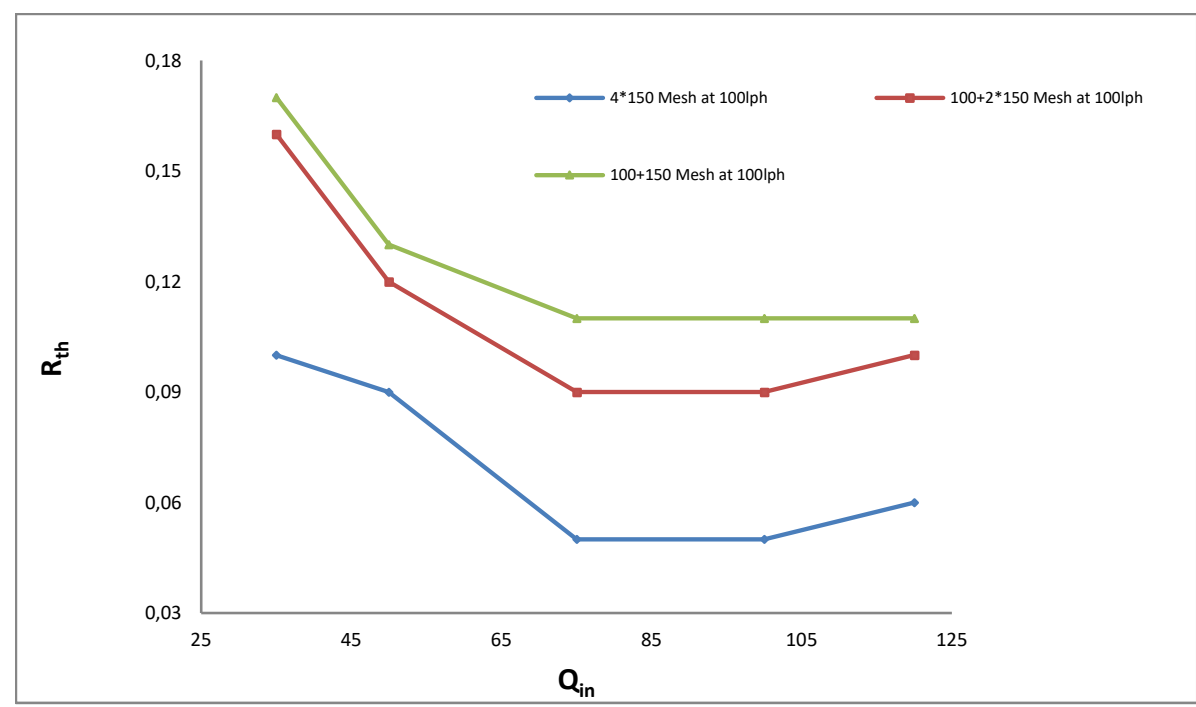

Figure 9. Thermal resistance for different heat with $\mathrm{CuO}$ nanofluid for different Mesh at $100 \mathrm{l} / \mathrm{h}$

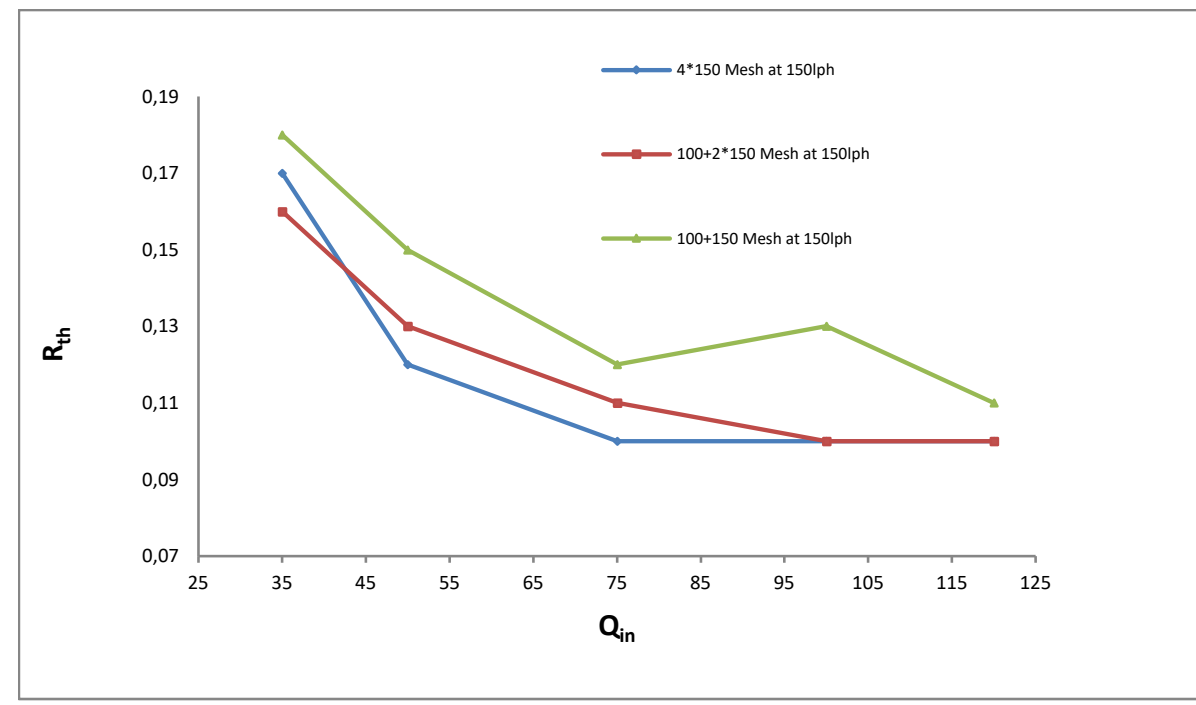

Figure 10. Thermal resistance for different heat input with $\mathrm{CuO}$ nanofluid for different Mesh at 150 l/h

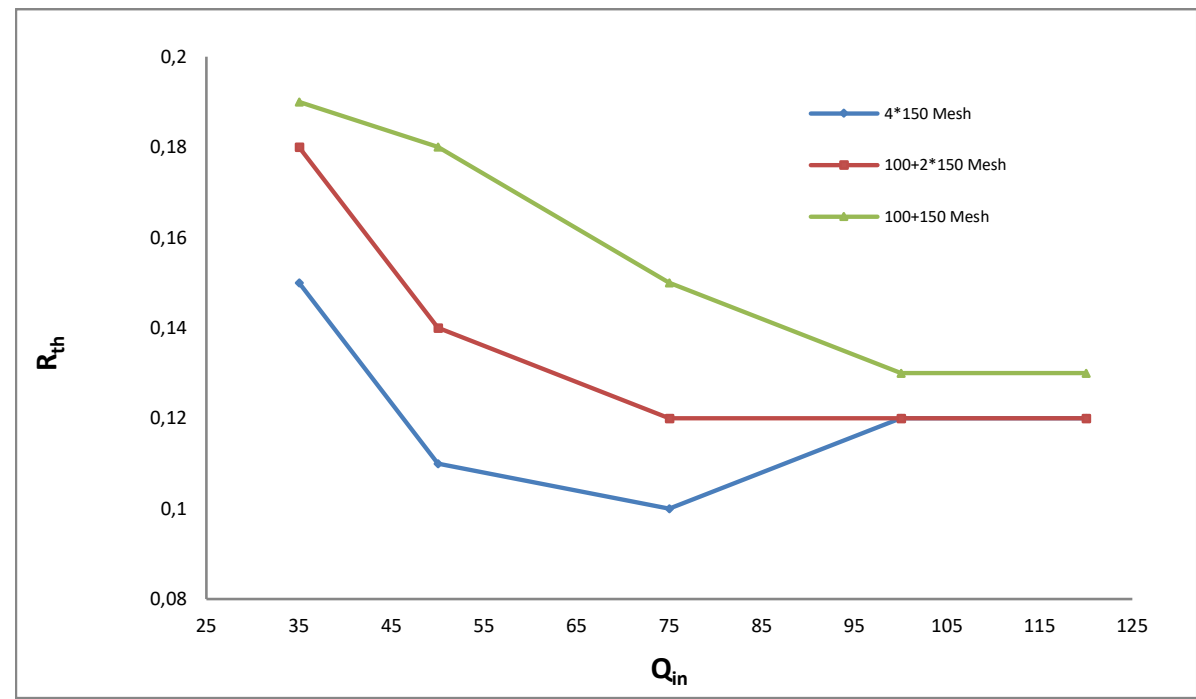

Figure 11. Thermal resistance for different heat input with water for different Mesh at $100 \mathrm{l} / \mathrm{h}$ 
Table 3. Wicks Configuration

\begin{tabular}{ll}
\hline Wick Composition & Thickness (mm) \\
\hline 4X150 Mesh & 0.34 \\
\hline $100+2$ X150 Mesh & 0.33 \\
\hline $100+150$ Mesh & 0.26 \\
\hline
\end{tabular}

\section{CONCLUSIONS}

An experimental investigation is carried out to determine the effect of $1.0 \%$ concentration of $\mathrm{CuO}$ nanoparticle mixed in water as base fluid on heat transfer characteristics of multilayer screen mesh wick heat pipe. Also effect of number of meshes on the heat transfer rate of multilayer screen mesh wick heat pipe has been investigated. Effects of varying mass flow rate on performance of heat pipe are also studied. The overall heat transfer coefficient is found to increase for $\mathrm{CuO}$ nanoparticle than that of water. In comparison between $\mathrm{CuO}$ Nano fluid and water when used as working fluid, $\mathrm{CuO}$ Nano fluid shows better heat transfer characteristics as compared to water. As the number of mesh increases, the heat transfer rate also increases. It is found that mesh with $4 \mathrm{X} 150$ have minimum resistance and high heat transfer rate for both working fluids. It is observed that in comparison to 100 mesh, 150 mesh shows better heat transfer rate. Considering the variation of mass flow rate, it can be conclude that at $100 \mathrm{l} / \mathrm{h}$ i.e. at lower mass flow rate better heat transfer rate is obtained. The heat pipe shows a higher thermal resistance initially, but eventually reduces with increase in heat input. $\mathrm{CuO}$ shows lesser thermal resistance than the water during initial period. Mesh can be increased only up to certain limit while using Nano fluid as a working fluid, because of occurrence of clogging of Nano particles in the mesh beyond certain limit. In condenser section, pipe wall temperatures increase towards the end where the coolant outlet pipe was located. The increase may be due to the gain of heat by coolant water flowing from inlet to outlet section of condenser.

\section{ACRONYMS}

$\begin{array}{ll}\mathrm{CuO} & \text { Cuprous Oxide } \\ \mathrm{CHF} & \text { Critical Heat Flux } \\ \mathrm{R}_{\text {th }} & \text { Thermal Resistance } \\ \mathrm{Q}_{\text {in }} & \text { Heat input } \\ \mathrm{Q}_{\text {out }} & \text { Heat Output } \\ \mathrm{Q} & \text { Heat transfer rate } \\ \mathrm{L}_{\text {eff }} & \text { Effective length of heat transfer } \\ \mathrm{L}_{\text {adiabatic }} & \text { Length of adiabatic section } \\ \mathrm{L}_{\text {cond }} & \text { Length of condenser section } \\ \mathrm{L}_{\text {evap }} & \text { Length of evaporator section }\end{array}$

\section{REFERENCES}

Brahim, T. and Jemni. A. (2012). Heat Pipe Simulation under critical conditions. Frontiers in Heat Pipes (FHP), 3(3), 033003. https://doi.org/10.5098/fhp.v3.3.3003

Brahim, T and Jemni. A. (2013). Effect of the Heat Pipe Adiabatic Region. J. Heat Transfer, 136(4), 042901, Copyright by ASME. https://doi.org/10.1115/1.4025132

Brahim, T and Jemni. A. (2016). Numerical case study of packed sphere wicked heat pipe using $\mathrm{Al}_{2} \mathrm{O}_{3}$ and $\mathrm{CuO}$ based water nanofluid. Case Studies in Thermal Engineering, 8, 311. http://doi.org/10.1016/j.csite.2016.09.002

Ersoz, M. A. and Yildız, A. (2016). Thermoeconomic analysis of thermosyphon heat pipes. Renewable and Sustainable Energy Reviews, 58, 666-673. https://doi.org/10.1016/j.rser.2015.12.250

Faghri. (1995). Heat Pipe Science and Technology, Taylor and Francis, London.

Ghanbarpour, M., Nikkam, N., Khodabandeh, R. and Toprak, M. S. (20150. Thermal performance of inclined screen mesh heat pipes using silver nanofluids. International Communications in Heat and Mass Transfer, 67, 14-20. https://doi.org/10.1016/j.icheatmasstransfer.2015.06.009

Hassan, H. and Harmand, S. (2015). Study of the parameters and characteristics of flat heat pipe with nanofluids subjected to periodic heat load on its performance. International Journal of Thermal Sciences, 97, 126-142. https://doi.org/10.1016/j.ijthermalsci.2015.06.009 
Kempers, R., Ewing, D. and Ching, C. Y. (2006). Effect of number of mesh layers and fluid loading on the performance of screen mesh wicked heat pipes. Applied Thermal Engineering, 26, 589-595. https://doi.org/10.1016/j.applthermaleng.2005.07.004

Lazardas, G., Nimmagadda, R. and Wongwises, S. (2013). Heat transfer performance of screen mesh wick heat pipes using silver-water nanofluid. Int. J. Heat and Mass Transfer, 60, $201-209$. https://doi.org/10.1016/j.ijheatmasstransfer.2012.11.037

Putra, N., Septiadi, W., Rahman, N. H. and Irwansyah, R. (2012). Thermal performance of screen mesh wick heat pipes with nanofluids. Experimental Thermal and Fluid Science, 40, 10-17. https://doi.org/10.1016/j.expthermflusci.2012.01.007

Solomon, A. B., Ramachandran, K., Asirvatham, L. G. and Pillai, B. C. (2012). Thermal performance of a heat pipe with nanoparticles coated wick. Int. J. Applied Thermal Engineering, 36, $106-112$. https:// doi.org/10.1016/j.applthermaleng.2011.12.004

Yang, X. F., Liu, Z. H. and Zhao, J. (2008). Heat transfer performance of a horizontal micro grooved heat pipe using CuOnanofluid. J. Micromech. Microeng, 18, 035038. https://doi.org/10.1088/0960-1317/18/3/035038

Yao, S., Leil, L., Deng, J., Lu, S. and Zhang, W. (2015). Heat transfer mechanism in porous copper foam wick heat pipes using nanofluids. International journal of heat and technology, 33(3), $133-138$. https://doi.org/10.18280/ijht.330320 